\title{
The Analysis on Artistic Character of Stone Culture in Feixian
}

\author{
Yanqing Hou $^{1, a}$ \\ ${ }^{1}$ Feixian School, Linyi University, Feixian, Shandong, P.R.China \\ a 1ydxmfl@126.com
}

\begin{abstract}
With the rapid development of economy and advance of social material and spiritual life, also along with people's pursuit of art, it has been popular to collect rare stones. Being the hometown of rare stones, Feixian has varieties of stones and has formed the rich Stone Culture that can go back to ancient times. Here I am trying to discuss the artistry of Feixian Stone from following aspects like its shape, space, decoration, property and so on, which will on the basis of the cultural practice and realistic perfection of Feixian Stone.
\end{abstract}

Keywords: Feixian Stone, artistry, the cultural practice of

Feixian Stone

\section{Introduction}

With the rapid development of economy and advance of social material and spiritual life, also along with people' pursuit of art, it has been popular among people to collect rare stones. Especially in traditional Chinese gardens, people tend to personified the stones or compare stones to animals, they make the stones their friends, their companion. They appreciate stones, and astonished by it, interested in it, they enjoy stones, or people usually say they worship stones, the word "worship" just tell people' appreciation on stones.

Being located in South Shandong, Feixian has a long history and rich culture. Because of its particular geological structure, Feixian has varieties of rare and beautiful stones. According to experts, Feixian Stone is the buried Taihu Stone and underground stone forest with the largest number of stone deposits and most vagarious stones. Feixian Tianjing Stone, the species unique in China, is clearly and vividly, and utterly natural. Feixian Yanzi Stone(the trilobites fossils), which has a history of more than 50 million years, is a kind of rare stone oryctocoenose, artistic objects made from this is quite fantastic. People of Feixian embody the characters of Shandong people with their honesty, simplicity and sincerity. Along with the long history of Feixian, the cultural vein of Yimeng, the cultural character of QiLu, the broad mind of Chinese nation, the brave deeds happened in Mt.Yimeng area during the War of Liberation, all the above express the cultural sprits of Feixian[1]. Such varieties of rare stones also create the Stone Culture of Feixian. here I will try to explore the artistry of Stone Culture of Feixian from following aspects.

\section{The Aesthetic Characteristics of Feixian Stone}

\subsection{The exterior characteristics.}

The characteristics of Feixian stone lies in its shape, grace, skeletons, crevice, delicacy and wrinkles. Feixian stone are born with the shape like people, animals or something else, they are different in sizes; the vivid image of stone embody its grace; the skeleton of it is strong and stubborn, and the outline of stone is clear; the crevice of it is impressive and the surface of it is has bright concaveconvex feeling; with holes of different sizes, Feixian stone shows great delicacy; the changeable wrinkles on surface of stone shows a sense of vicissitudes ,.

\subsection{The spatial characteristics.}

The weight of Feixian Stone range from a few kilograms to tones. Every single rare stone can make a landscape. It can be classified into Landscape Stone, Symbolic stone, Screen-wall Stone, Moral Stone, Artificial Stones, Revetment Stone, Headstone and so on, each kind of stone has particular spatial feature of itself.

Usually being put on garden Greenland or under the tree, the Landscape Stone can be used as table, stool or platform. Generally speaking, the size of them is large and is able to make a scenery by itself, or combined with something else. Symbolic Stone is often used to show the image of the company, enterprise or city. sometimes people will carve words on it, to make a plaque in memory of our ancestors or someone important, or make signposts. Being set at the entrance of a building or the top of the road, Screen-wall Stone usually plays its role of blocking the scene, setting off the scenery and achieving spatial balance. Moral Stone, as can be seen from the name, usually contains certain kind of philosophy. Revetment Stone is usually set up near the river, it scattered high and low, presents a natural exquisite beauty. Artificial Stones can be used to form rockery or cave. Headstone is suited for collecting or indoor furnishings.

\subsection{The decorative style of Feixian Stone in landscape design}

Being used to decorate the Gardens or courtyard, Feixian Stone can make a simple and elegant scenery by 
itself or combined with others. In landscape designing, the decorative style of Fixian Stone consists of placing it separately, scattering it, piling it up and combining it together. Stone suited for being placed separately must be the one which has full composition, and is simple, quaint. Scattering it means to choose the stones that is special or same in shape to make a set of landscape by scattering it do beautify the foot of wall or beside other buildings, so as to keep in harmony with the surroundings. Piling it up means to pile Feixian Stones of different kinds of shapes into caves or hills, and to form the same textures to looks like they should have been an integrated mass. Combining it means to rearrange the stones with special images distinctly to form a particular theme, and the overall result must be attached great importance. The tiny Feixian Stone like Headstone, is on display mainly for decoration. The landing surface and front facet of it is as important as the platform under it.

\subsection{The property of Feixian Stone}

It covers nature, singularity, humanity, beauty, collection and environmental benefits. The nature of Feixian Stone consists of its shape, color, texture and quality. The singularity of it means the difference that Feixian Stone has made through the way it combines with each other from the normal stones. Apart from this, the singularity give birth to the beauty and artistry. Humanity means the sociality of the object of which the stone has reflected. For or different kinds of stone, the humanity is different. The humanity of rare stone with image that reflects the social phenomenon will be higher. Beauty is the subjective response of aesthetic subject to the nature, singularity and science of rare stones, is affected synthetically by the influence of rare stone, the aesthetic ability of the aesthetic subject and the aesthetic relation between subject and object. For example, the trilobites fossils, determined by its external form and scientific value, it has great ornamental and collection value.

\section{The Impact of Cultural Practice of Feixian Stone on The Art Conception}

The cultural practice of Feixian Stone provide us with rich aesthetic experiences, and in combination with aesthetical theory, we get to know the aesthetic characteristics of Feixian Stone basically. It can be summarized as follows.

\subsection{Feixian Stine has the structure of artworks}

As the Introduction to Art has mentioned : The artwork is made up of text(direct carrier) and carrier(indirect carrier). The so-called text is the artwork in general, it consists of language, structure, image and theme, is a direct medium influenced by artistic subject and act on the object. The socalled carrier is the material means on which artwork depends, is the media between artwork and subject[2]. So we may say that the image, vision, charm and theme of Feixian Stone is direct carrier, and is ideological factors. The shape, color, texture and quality of it is indirect carrier, is material means to shape artworks. Two kind of carriers decompose and integrate the social practice.

\subsection{Feixian Stone has aesthetic function of artwork}

In the forms of beauty, Feixian Stone consists of realistic beauty and reflective beauty. Natural beauty is the property of Feixian Stone. The shape, color, texture and quality of Feixian Stone makes it possible to be the singular aesthetic object to create formal beauty. Feixian Stone covers all kinds of beauty in shape or category.

In the forms of nature and characteristics of beauty, the nature of Feixian Stone is the same as the nature of normal beauty, the creativity of beauty of Feixian Stone is embodied in a series of activities which consists of collecting, decorating, appreciating and displaying and in the reasonable discovery during the process of appreciating rare stones.

In the forms of beauty generation, there are some similarities as well as some differences between the aesthetics generation of Feixian Stone and normal beauty. The similarity is that both are based on social practice, both has experiencing the process from practical forms to aesthetic forms, from unconscious to conscious, from superficial to thorough and meticulous. The difference is that the aesthetics of Feixian Stone has learned from the aesthetical pattern or experiences of painting and sculpture, it is guided by the modern aesthetic theory.

\section{The Comparison of Feixian Stone and Traditional Culture in Artistry}

There are relations and differences between Feixian Stone and traditional culture in artistry. The cultural artistry means that we can reflect the social life and show our feelings as vividly, precisely, and clearly as possible through artistic methods. The expressiveness of different kinds of arts is different. In plastic art, the artistry means that artists will show their aesthetic artistic conception through lines, color, lighting, composition and contrast. For plastic art, the imago was founded before artistic image. The lines, color, lighting, composition and contrast are emotional methods mate mastered by artists to change the imago into artistic image[3]. Feixian Stone is also a kind of space art, also shows the degree the artist has reached when creating their own aesthetic artistic conception through artistic image. This the similarity of them. While the difference is that for Feixian Stone art, the artistic image is founded before imago. The shape, color, texture and quality are created by nature the artist, we humans can do nothing in means of creation. What we can do is merely to follow the natural artists to filter and choose the social and natural image provided by social practices of human, this, is 
creation in higher level. So, we can say that the rare-atone art is art of nature, is art of discovery.

\section{CONCLUSIONS}

The Comparison of Feixian Stone and Plastic Art in Artistry

There are relations and differences between Feixian Stone and plastic art in artistry. Strictly speaking, the Feixan Stone art can be divided into two parts: the practical art and aesthetic art. The practical is the skills and experiences we need during the whole technological process from the collecting of stones to the displaying. Aesthetic art is the aesthetic ideology formed when artists or rare-stone enthusiasts are appreciating the artistic image and aesthetic factors contained in rare stones. The artist are able to summary the practical experiences of rare-stone culture and reveal its aesthetic laws from the angle of combining the rare-stone cultural practice with aesthetic philosophy.

" If flowers can speak then the troubles may come, while the stone is most lovely because of its silence." Due to the join of rare-stone art, the conception of art and artwork has been enriched. The discovery and application of Feixian Stone has caused great response in Chinese garden architecture circles and geology. Although had been discovered later than other famous mountains, once it awakes, it shock the whole China and becomes the most special. Compared with Taihu Stone, it has a much more independent image: the Taihu Stone can be piled together into hills while the Feixian Stone can make a hill by itself. Compared with Lingbi Stone, it is more graceful. The Lingbi Stone mainly changes in regular parts, while the
Feixian Stone changes more flexibly. Compared with Yingde Stone, it is much more pretty and lovely than grey and heavy[4]Feixian Stone is just itself, it is new species with its own characters, and even surpass the its ancestors in Chinese stone family, it is a late bloomer, it is to be regarded with respect, is a rising star in stone family of China.

\section{Acknowledgments}

The authors wish to give their sincere thanks to the editor and the anonymous referees for their valuable suggestions and helpful comments which improved the presentation of the paper.

\section{References}

[1] Local chronicles compiling committee of Feixian, The history of rare stones in Feixian [M].Beijing: China Publishing House, 2006.

[2] Editorial Board of "The Complete Study of Chinese Artwork Collection” , The Complete Study of Chinese Artwork Collection-rare stone [M].Changchun: Women and Children Press of North China,2007.

[3] Li Shengli, Introduction to Art [M]. Communication University of China Press,2014.

[4] Cultural and History Data committee of Feixian PPCC, The Complete Cultural and Historal Data of Feixian [M].Jinan: Shandong Publishing House of Map, 2003. 